\title{
Apresentação
}

\section{Os sentidos da crítica de arte na imprensa brasileira (1950-2000)}

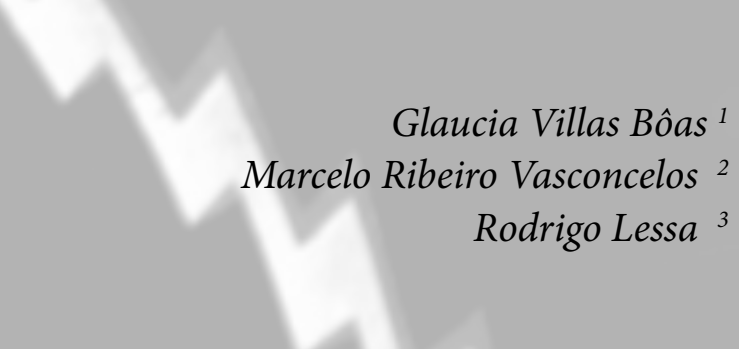

Este dossiê reúne sete artigos que retomam aspectos da crítica de arte publicada em jornais cariocas, paulistas e baianos na segunda metade do século XX. De lá para cá, a crítica veiculada pela imprensa arrefeceu e se transformou com o aparecimento de novos suportes e novas demandas do mercado editorial. Mas não foi só isso. As mudanças pelas quais a arte vem passando, com a emergência da arte contemporânea na década de 1960 (ERBER, 2015), se fizeram notar em alterações das atividades mais rotineiras do mundo artístico, incluindo o questionamento dos antigos métodos de ajuizar e mediar o trabalho artístico utilizados pelos críticos. Os curadores de exposição tomaram o lugar de relevância antes ocupado pelos críticos, e até mesmo pelos artistas, no juízo de alguns estudiosos (AMARAL, 2006). Jovens procuram galeristas, submetendo-se a editais de todo tipo para ter uma chance de expor suas obras ou fazer uma residência artística. Raros são aqueles que ainda procuram um crítico para avaliar seus trabalhos. Neste sentido, o dossiê evidencia o desenrolar dessas mudanças, que ao modificar o perfil do mundo da arte, nem sempre agradaram ao público (HEINICH, 1997).

Muito embora o encolhimento da crítica apareça como a tônica de sua condição atual, Luiz Camillo Osório afirma em Razões da Crítica (2005), que de nada serve a nostalgia dos bons tempos da circulação da crítica nos jornais, chamando a atenção justamente para a urgência do exercício judicativo no momento em que "não temos mais nenhuma certeza a priori sobre como uma obra cria sentido [...]Julgar implica diferenciar, produzir diferenças" ( $\mathrm{p} 9$ ). Para ele, a crítica permanece viva em novos desdobramentos contemporâneos, a exemplo das atividades curatoriais nos museus, refazendo-se a si própria a partir das exigências da época e moldando-se aos espaços que lhe são concedidos. Antes de tudo, a adesão pela sua permanência se justifica em nome da pluralidade bem como da liberdade experimental da arte comprometida com o desconhecido e o surpreendente.

Os artigos que integram Os sentidos da crítica de arte na imprensa brasileira (1950-2000) revelam especificidades do mundo artístico brasileiro, revendo as ideias polêmicas adotadas pelos seus críticos. Durante a leitura, destaca-se a defesa intransigente da arte abstrata sobre a arte figurativa de meados do século passado a denotar um processo de intectualização da linguagem artística. A maior parte dos textos críticos mencionados se remete ao movimento concreto e neoconcreto, em detrimento de artistas figurativos ou mesmo de artistas abstratos que não se filiaram às correntes concretas. Mas, os adeptos do concretismo não foram poupados da crítica de seus colegas de ofício, sobretudo

1 Professora Titular do Programa de Pós-Graduação em Sociologia e Antropologia (PPGSA) da Universidade Federal do Rio de Janeiro (UFRJ). Doutora em Sociologia pela Universidade de São Paulo (USP).

2 Doutor em Sociologia pelo Programa de Pós-Graduação em Sociologia da Universidade Estadual de Campinas (UNICAMP).

3 Professor de Ensino Básico, Técnico e Tecnológico no Instituto Federal de Educação, Ciência e Tecnologia Baiano (IF Baiano), Campus Alagoinhas. Doutor em Ciências Sociais pela Universidade Federal da Bahia (UFBA). 
nas primeiras décadas de 1950 e 1960, o que permite ao leitor tomar conhecimento das diferentes posições apregoadas pelos especialistas relativamente às linguagens artísticas que emergiam naquela época. Outra questão de peso refere-se à indagacão sempre renovada do que é e não é arte, inscrita nos artigos sobre o estatuto da linguagem dos quadrinhos, da arquitetura e do cinema, numa tentativa de distinguir as fronteiras da crítica.

A Enciclopédia Itaú Cultural diz que "em sentido estrito, a noção de crítica de arte diz respeito a análises e juízos de valor emitidos sobre as obras de arte, que, no limite, reconhecem e definem os produtos artísticos". Mas para a Wikipedia. A Enciclopédia Livre faz circular o seguinte verbete:

A crítica de arte é um gênero, entre literário e acadêmico, inclusive periodístico que faz uma avaliação estética das obras de arte, artistas ou exposições, em princípio de forma pessoal e subjetiva, mas baseandose na História da Arte e suas múltiplas disciplinas (por exemplo a sociologia, antropologia, arqueologia, história e a psicologia), atribuindo valor à arte de acordo com seu contexto ou evolução. É a um só tempo, valorativa, informativa, e comparativa, redigida de forma concisa e amena, sem pretender ser um estudo acadêmico mas aportando dados empíricos e contrastáveis.

Se os verbetes das enciclopédias online, cada vez mais consultadas, sublinham a crítica como discurso ou texto, o inglês Terry Eagleton (2005) relembra no seu A função da Crítica que, ao longo da história da cultura, a divisão do trabalho intelectual foi se impondo e acarretando a especialização dos discursos e dos saberes. Ao adotar uma perspectiva social e histórica, o autor mostra como os "homens de letras", portadores de saberes humanistas, foram substituídos pelos críticos acadêmicos, provocando uma crescente profissionalização e compartimentação do conhecimento. Diga-se aqui que esse processo não ocorreu apenas na esfera da crítica mas constitui uma característica relevante da modernidade. De todo modo, as teses de Eagleton servem para abalizar sociologicamente a formação dos críticos de arte e as mudanças que se operam naquele campo de atividade.

No contexto brasileiro, os críticos literários começam a ceder lugar aos críticos de arte no contexto do pós guerra. Note-se que, diferente da mudança apontada por Eagleton, no Brasil, o afastamento dos críticos literários, homens de letras, ocorreu em larga escala pela emergência de novo repertório conceitual voltado para aspectos formais da obra de arte. Tampouco, conforme mencionado por Eagleton referindo-se à Inglaterra, o processo de profissionalização da crítica, no país, correspondeu a sua entrada definitiva para universidade, apesar de alguns críticos pertencerem a elas (PONTES, 1998). A trajetória de Mário Pedrosa é modelar nesse sentido. Bacharel em Direito e militante político, Pedrosa teve forte ligação com o mundo das artes e da música. Em sua tese À Espera da Hora Plástica (2014), Tarcila Formiga mostra com muita propriedade que o despontar do crítico de arte em Mário Pedrosa não ocorreu repentinamente a partir da avaliação crítica da obra da artista alemã Kaethe Kollwitz (em 1933), mas de processo através do qual Pedrosa adquire um novo repertório. Já Marcelo Ribeiro (2018) aborda o exílio de Mário Pedrosa em Nova Iorque (1938-1945), procurando entender sua "conversão" (ARANTES, 2004) ao abstracionismo como parte de sua vivência em meio aos New York Intellectuals, círculo de críticos americanos que defendeu a aproximação entre modernismo e radicalismo, baseada na rejeição da mercantilização da arte e na consideração dos direcionamentos ideológicos, quaisquer que fossem, como um empecilho para liberdade de criação.

Ao voltar do exílio nos Estados Unidos, Pedrosa assumiu uma coluna de crítica de arte no antigo Correio da Manhã, renovando-a com abordagem que realçava as qualidades formais do objeto artístico em detrimento do tema ou assunto representado. Para ele interessavam as qualidades intrínsecas da obra de arte que a distinguiam como um todo à parte. Nunca é demais relembrar que a posição de Pedrosa se sobressaiu entre as demais como um dos principais teóricos e defensores do concretismo, movimento artístico preponderante nas artes visuais brasileiras da década de 1950.

Embora com espaço limitado e público eclético, os jornais tornam-se veículos privilegiados para a circulação das ideias críticas sobre a arte, e para as disputas e polêmicas resultantes das visões 
distintas dos críticos. José Carlos Durand (1989) observou uma afinidade entre a imprensa e as artes visuais que se expressava, sobretudo, por uma busca por diferenciação no acirrado mercado editorial brasileiro e pela busca por prestígio junto ao público. Assis Chateaubriand foi um exemplo notável de tal fenômeno, na medida em que era proprietário do enorme conglomerado de jornais Diários Associados, colecionador e financiador de empreendimentos como o Museu de Arte de São Paulo (MASP).

No cinema, o impulso que a arte moderna imprime de busca pela liberdade absoluta diante da sociedade recebe como contraponto uma crítica cinematográfica voltada para o destaque de sua humanidade e de seu caráter social. Se é verdade que, como uma arte relativamente recente, o filme termina por enfrentar dilemas pelos quais suas antecessoras já haviam passado, como a sua afirmação como expressão única diante das outras artes e em particular do campo das artes visuais, o caminho trilhado pelos críticos acompanha a disposição mimética que a estética cinematográfica apresentou em sua origem e desenvolvimento no âmbito do século XX. Qual seja, a de se aprofundar sobre diversos os aspectos da relação dos indivíduos com o mundo. Neste sentido, a preocupação em identificar de que maneira um filme capta ou não a complexidade de um fenômeno político, como o impacto de uma guerra sobre a população de um país, ou ainda se uma determinada estética é capaz ou não de suscitar o envolvimento do espectador com os dramas humanos, se tornam o material fundamental da crítica de cinema. A crítica responde pela comunicabilidade entre a obra e o mundo que parece longe de questionamentos diante da força da imagem fílmica.

No caso brasileiro, a relação entre cinema e sociedade é abordada pela crítica em termos nacionais e locais. Diante do potencial que o filme apresenta para alcançar as massas de um país com proporções continentais, temas como a acessibilidade da linguagem fílmica, os assuntos abordados, a capilaridade diante das questões sociais e o lugar da experiência local se mostram presentes nas preocupações de críticos pioneiros, como Paulo Emílio Sales Gomes, e se perpetuam diante das possibilidades animadoras da expressão fílmica absorver em termos estéticos as mais diversas questões e contradições do mundo moderno. Como uma manifestação singular desta experiência, a crítica de cinema na Bahia, realizada por Walter da Silveira e André Setaro se desenvolveu também sob este prisma. Sempre preocupados em converter a reflexão sobre o cinema e o juízo sobre os filmes em um modo de animar a cena local, os dois ensaístas espalharam em periódicos como o Jornal da Bahia e o Jornal da Cidade suas recepções da produção nacional e internacional, procurando pensar as especificidades do cinema e a maneira como se aprofundava sobre a condição humana. A reflexão sobre os filmes e os juízos de valor sobre a produção em cada período, dessa maneira, é acompanhada pelo propósito prático de expandir os círculos de acompanhamento do cinema no estado e, ao mesmo tempo, pensar a sua configuração diante de uma sociedade em transformação. Trajetória que os levou não apenas a se tornarem influentes no surgimento de cineclubes e espaços de fomento ao cinema na Bahia, como também propositores de conceitos e teorias sobre a estética desta expressão e sobre suas condições históricas de desenvolvimento.

A partir dos anos 1950, a crítica de arte caminhou de vento em popa nos jornais e suplementos literários brasileiros. Alcançou autoridade para reconhecer os "verdadeiros objetos artísticos", imprimindo sentido e realçando a pluralidade das artes visuais. Os trabalhos aqui publicados pretendem contribuir para o melhor entendimento dos valores inerentes às práticas das artes visuais contemporâneas e atuais, mostrando seus desafios e limites no passado.

Um exemplo das disputas frequentes sobre a interpretação da obra de um artista é discutido em Alfredo Volpi na Berlinda: crítica de arte e projetos estéticos concorrentes de Antônio Brasil Jr. O autor discute a crítica da obra de Volpi elaborada por Theon Spanudis, artista e colecionador ele próprio de obras de Volpi, comparando-a com aquela do artista e crítico Waldemar Cordeiro a respeito do modo "construtivista" da obra de Volpi. Com base na documentação reunida no Fundo Theon Spanudis depositada no Instituto de Estudo Brasileiros da Universidade de São Paulo, a pesquisa de Antônio 
Brasil Jr sobre o pintor Alfredo Volpi deixa entrever um aspecto das pelejas dos críticos de arte na década de 1950.

Contrariando o ceticismo relativamente ao papel da crítica de arte à arquitetura, Mario Pedrosa organizou, em 1959, o Congresso Extraordinário de Críticos de Arte com o apoio da Associação Internacional de Críticos de Arte, sediando o evento em Brasília, em seguida em São Paulo no Pavilhão Ciccillo Matarazzo, onde se realizava a V Bienal e no Rio de Janeiro no Museu de Arte Moderna. Críticos renomados dos mais diversos países como Giulio Argan, Meyer Shapiro, Herbert Read, Tomás Maldonado entre outros se deslocaram para os santuários do modernismo brasileiro, que se construíam naquela época, para discutir o projeto da cidade de Brasília. Poucos eventos relacionados à crítica de arte, provavelmente, tiveram um caráter tão peculiar quanto esse no qual os debates se realizavam paralelamente à vivência do objeto posto em questão. A Crítica de arte na imprensa carioca e o debate sobre Brasília no congresso da AICA (1959) de Marcelo Ribeiro dá conta do noticiário e da crítica veiculada nos jornais cariocas, mostrando o dissenso relativamente ao projeto e à posição de Mário Pedrosa resumida na expressão, Brasília - síntese das artes, fio condutor dos debates proposto pelo crítico.

Segue o artigo de Layssa Bauer von Kulitz, A Disputa sobre os Quadrinhos: infância, arte e censura na imprensa brasileira, que descortina uma faceta importante mas pouco conhecida do debate sobre a natureza artística das histórias em quadrinhos. Além de passatempo, as histórias em quadrinhos se tornaram objeto de um debate público em finais da década de 1940, que separava os adeptos das qualidades educacionais e lúdicas dos quadrinhos e os críticos contudentes de seus efeitos perversos sobre a juventude. De acordo com a autora a polarizacão entre censura e consagracão dos quadrinhos expressava posições normativas quanto à definicão de arte, revolvendo dessa maneira as fronteiras entre as artes visuais, a literatura e os quadrinhos.

Da outra forma, a leitura do artigo Crítica Cinematográfica na Bahia do século XX: os olhares de Walter da Silveira e André Setaro sobre a relação entre cinema e sociedade, de autoria de Rodrigo Lessa, Bruno Vilas Boas Bispo e Filipe Baqueiro, discute os limites entre a crítica de arte e a crítica cinematográfica, estabelecendo distinções. O texto evidencia singularidades da crítica cinematográfica, tal como sua tendência a vincular a linguagem fílmica ora com elementos estéticos ora com elementos não estéticos, históricos e culturais. Os autores revisitam duas geracões de críticos baianos representadas nas figuras de Walter da Silveira (1915-1970) e André Setaro (1950-2014). Ao comparar os prismas de análise diferenciados de cada um deles, os autores revelam que enquanto Walter da Silveira enfatiza a centralidade temática, André Setaro acentua a importância da linguagem fílmica para a crítica.

No artigo intitulado Aspectos da crítica sobre jovens artistas nas páginas do Jornal do Brasil (19502000), Guilherme Marcondes questiona os motivos pelos quais a imprensa dedicou tanto recurso e espaço para a crítica das obras de arte de jovens em fase de construcão de carreira. Pesquisando o antigo Jornal do Brasil, o autor revela como os jovens são apresentados ao público a partir de atributos que não dizem respeito exclusivamente aos seus trabalhos artísticos mas a qualidades pessoais ou dados relevantes de sua biografia; em seguida discute sua hipótese sobre o interesse institucional da novidade, frisando que para muitos agentes que participam do mundo artístico, tais como historiadores e críticos de arte, somente os jovens são portadores de novas poéticas que eventualmente podem vir a mudar tendências consolidadas. Descobrir dentre os jovens aqueles realmente "talentosos" seria um privilégio para os críticos.

A legitimação de Mário Pedrosa como crítico de arte: a recepção na imprensa do livro Arte, necessidade vital de autoria de Tarcila Soares Formiga discute a recepção do livro Arte, necessidade vital, com textos escritos durante o período de 15 anos e lançado por Mário Pedrosa, em 1949. A autora defende o argumento de que a recepção positiva do livro na imprensa, coincidiu com a redacão de 
Da natureza afetiva da forma na obra de arte com as fundamentos teóricos apregoados por Pedrosa para a critica de arte além de outras atividades de Pedrosa, favorecendo o seu reconhecimento como um dos principais críticos naquela época.

O texto de Tálisson Melo de Souza Criticar / criar / curar arte: Sheila Leirner e sua "Grande Obra” na imprensa e em exposições destrincha as concepções da crítica e curadora Sheila Leiner sobre a producão artística contemporânea que relaciona crítica, curadoria e criação e serviram para fundamentar o seu projeto para a $18^{\text {a }}$ Bienal Internacional de Arte de São Paulo realizada em 1985, que marcou com sua ousadia a história das bienais, acentuando a tensão entre os papéis da crítica e da curadoria.

Cabe dizer finalmente que a motivação para a escrita dos artigos desse dossiê e sua publicação se deve ao incentivo do Projeto Imprensa e circulação de ideias: o papel dos periódicos nos séculos XIX e XX coordenado por Isabel Lustosa da Fundação Casa Rui Barbosa e Tania Regina de Luca da Universidade Estadual Paulista. Neste amplo e relevante projeto coube a coordenação do subprojeto A crítica de arte em circulação nos periódicos paulistas e cariocas da segunda metade do século XX a Glaucia Villas Bôas. Queremos aqui expressar nossos agradecimentos a Isabel Lustosa e Tania de Luca, e a Raphael Bispo, editor de Teoria \& Cultura que muito gentilmente aceitou o projeto do dossiê.

\section{Referências Bibliográficas}

AMARAL, Aracy. O Curador como Estrela. In: AMARAL, Aracy. Textos do Trópico de Capricórnio - Artigos e Ensaios (1980-2005): Bienais e artistas contemporâneos no Brasil. São Paulo: Ed. 34, v. 3, 2006.

ARANTES, Otília. Mário Pedrosa: Itinerário Crítico. São Paulo: Cosac\&Naify, 2004.

DURAND, José Carlos. Arte Privilégio e Distinção: artes plásticas, arquitetura e classe dirigente no Brasil, 1855-1985. São Paulo: Perspectiva,1989.

EAGLETON, Terry. The Function of Criticism. Londres: Verso, 2005

ERBER, Pedro. Breaching the Frame. The Rice of Contemporary Art in Brazil and Japan. California, University of California Press, 2015

FORMIGA, Tarcila Soares. À espera da hora plástica: o percurso de Mário Pedrosa na crítica de arte brasileira. Rio de Janeiro. Tese (Doutorado em Sociologia), Programa de Pós-graduação em Sociologia e Antropologia, UFRJ

HEINICH, Nathalie. Outside Art and inside artists: gauging public reactions to contemporary public art. In: ZOLBERG, Vera L. e CHARBO, Joni Maya (Orgs.). Outsider Art: Contesting boundareis in contemporary culture, Cambridge, Cambridge University Press, 1997.

PONTES, Heloisa. Destinos Mistos: Os críticos do Grupo Clima em São Paulo (1940/68), São Paulo, Companhia das Letras, 1998.

RIBEIRO VASCONCELOS, Marcelo. O Exílio de Mário Pedrosa nos Estados Unidos e os New York Intellectuals: abstracionismo na Barbárie. Tese (doutorado em sociologia) - Instituto de Filosofia e Ciências Humanas, UNICAMP, Campinas, 2018. 
OSORIO, Luiz Camillo. Razões da crítica. Rio de Janeiro, Jorge Zahar Editor, 2005.

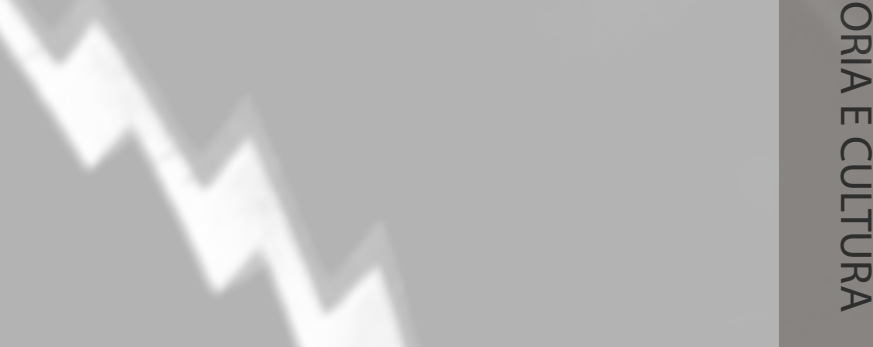

